\title{
On Appeals to Nature and their Use in the Public Controversy over Genetically Modified Organisms
}

\author{
ANDREI MOLdOVAN \\ Departamento de Filosofía, Lógica y Estética \\ Universidad de Salamanca \\ Salamanca, Spain \\ mandreius@usal.es
}

\begin{abstract}
In this paper I discuss appeals to nature, a particular kind of argument that has received little attention in argumentation theory. After a quick review of the existing literature, I focus on the use of such arguments in the public controversy over the acceptability of genetically-modified organisms in the food industry. Those who reject this biotechnology invoke its unnatural character. Such arguments have received attention in bioethics, where they have been analyzed by distinguishing different meanings that "nature" and "natural" might have. I argue that in many such appeals to nature the main deficiency of these arguments is semantic, in particular, that these words cannot be assigned a determinate meaning at all. In doing so, I rely on semantic externalism, a widely accepted theory of linguistic meaning.
\end{abstract}

Résumé: Dans cet article, je discute de "l'appel à la nature", un type d'argument particulier qui a reçu peu d'attention dans la théorie de l'argumentation. Après un rapide examen de la littérature existante, je me concentre sur l'utilisation de tels arguments dans la controverse publique sur l'acceptabilité des organismes génétiquement modifiés dans l'industrie alimentaire. Ceux qui rejettent cette biotechnologie invoquent son caractère peu naturel. Ces arguments ont retenu l'attention en bioéthique, où ils ont été analysés en distinguant différentes significations que "nature" et "naturel" pourraient avoir. Je soutiens que dans de nombreux cas d'appel à la nature, la principale lacune de ces arguments est la sémantique, en particulier le fait qu'on ne peut attribuer aucune signification déterminée à ces mots. Ce faisant, je m'appuie sur l'externalisme sémantique, une théorie largement acceptée du sens linguistique.

Keywords: appeal to nature, fallacy; ambiguity; deference; semantic externalism; meaning; genetically modified organisms; GMOs. 


\section{Introduction}

The aim of this paper is to discuss what is sometimes called "the fallacy of appeal to nature". While the label is widely used in informal discussions of fallacies, I was not able to find a discussion of it in the academic literature devoted to argumentation theory. However, appeals to nature are analyzed in other academic disciplines. After a quick review of the discussion of the fallacy in non-academic and academic forums, I focus on the use of such arguments in the debate over food obtained from genetically modified organisms (GMOs, henceforth). I choose this particular case study because there is a significant body of literature in academic journals devoted to this topic. In this literature these arguments are analyzed by distinguishing different meanings that "nature" and "natural" might have. Some authors argue that on all possible disambiguations of these words such arguments are bad, others suggest that on some interpretations the arguments have a certain force. I propose an alternative analysis, on which the problematic nature of (at least some of) these arguments stems from the fact that the word "nature" or "natural" fails to have an identifiable meaning. In doing so, I rely on semantic externalism, a widely accepted theory of linguistic meaning.

\section{The fallacy of appeal to nature}

The fallacy of appeal to nature is widely referenced on web pages and non-academic books dedicated to critical thinking. According to Bo Bennet, author of the website Logically Fallacious (www.logicallyfallacious.com), an appeal to nature is an argument that has one of the following two forms:

1. Premise $1: \mathrm{N}$ is natural.

Premise 2: Everything that is natural is good.

Conclusion: Therefore, $\mathrm{N}$ is good.
2. Premise 1: U is unnatural.

Premise 2: Everything that is unnatural is bad. Conclusion: Therefore, $\mathrm{U}$ is bad. 
There are different versions of the argument in which good/bad is replaced with right/wrong, healthy/unhealthy, ethically acceptable/ethically unacceptable, good solution to a problem/bad solution to a problem, or some other pair of evaluative terms. An example of the fallacy of appeal to nature that instantiates the form in (1) is to be found in a 2013 interview with Gwyneth Paltrow, where she expresses her view of the effects of sunbathing on health:

3. "We're human beings, and the sun is the sun - how can it be bad for you? I think we should all get sun and fresh air. I don't think anything that is natural can be bad for you - it's really good to have at least 15 minutes of sun a day." (quoted in the Canadian journal National Post, July $10^{\text {th }}, 2013$; italics added)

In this case, $\mathrm{N}$ is sunbathing, and the second premise in (1) is explicitly stated in the italicized sentence.

However, in other cases the second premise is not explicitly stated. Often the argument is reduced to calling something "unnatural" in order to reject it. Corvino (2013: p. 78) analyzes contexts in which the claim that homosexuality is not natural is used with the purpose of rejecting gay rights. Thus, Christian artists Angie and Debbie Winans' song "Not Natural" contains the following lyrics, with reference to homosexuality:

4. "It's not natural / No, that's not the way God planned / It's time for the world to understand."

Clearly the three lines quoted have an argumentative force. The listener is invited to infer that homosexuality is morally unacceptable, but there is no assertion made that everything that is unnatural is morally unacceptable. Most appeals to nature are of this kind, in the sense that the universal premises of (1) and (2) are not explicitly stated. Is this premise implicitly assumed? Given that many people would take it to be a controversial claim, if not a straightforwardly false one, it is not charitable to assume that the arguer takes it for granted. So, probably, a better reconstruction of the argument does not include the second premise in (1) and (2). Gary N. Curtis, author of Fallacy Files (www.fallacyfiles.org), does not introduce it into the reconstruction of such arguments. Thus, instead of (1) we get (5), and instead of (2), we get (6): 
5. Premise $1: \mathrm{N}$ is natural.

Conclusion: Therefore, $\mathrm{N}$ is good.
6. Premise $1: \mathrm{N}$ is unnatural.

Conclusion: Therefore, $\mathrm{N}$ is bad.

Why are arguments of this form usually considered fallacies? Different diagnoses of the problem with such arguments have been offered. According to

Curtis (http://www.fallacyfiles.org/adnature.html), the problem is the following:

The word "natural" is loaded with a positive evaluation, while "unnatural" contains a negative evaluation. So, to call something "natural" or "unnatural" is not simply to describe it, but to praise or condemn it. As with other loaded words, unless such concealed evaluations are backed up by other evidence, they will beg the question.

The use of loaded words in argumentation, Curtis notes, can generate a version of the fallacy of begging the question. The suggestion is that when we call $\mathrm{N}$ "unnatural" we are implicitly evaluating it as negative; and so, the conclusion that $\mathrm{N}$ is bad (or in some sense, negatively valued) simply follows analytically from the premise; but the claim made in the premise that $\mathrm{N}$ is to be valued negatively has not been backed by any argument, and so, the argument begs the question. But then why would the audience accept the premise that $\mathrm{N}$ is unnatural, given its unwarranted evaluative component? Curtis' suggestion is that the word contains a concealed evaluation of $\mathrm{N}$, which is somehow snuck into the premise of the argument without any backing.

I find two problems with this analysis of the fallacy. The first one concerns this last claim that the evaluative component of the meaning of "natural" is concealed. The audience is formed of speakers who are expected to be able to detect whether the word has an evaluative dimension or not, in virtue of their linguistic competence. Consider typical examples of evaluative words, such as "bunny" (for "rabbit"), or the use of pejoratives such as "cur" (for a mixed-breed dog). A competent speaker can easily identify the evaluative components of these words and separate them from their descriptive component. But then why would "natural" be special, and why would its 
evaluative component be concealed from the speakers? Unless this claim is backed by arguments, I see no reason to accept it. ${ }^{1}$

The second problem with Curtis's claim that "natural" has an evaluative component is that there are uses of "natural" that do not carry any evaluative content, such as in "natural language" or "natural disaster". In response, a defender of the approach discussed here might suggest that the word is ambiguous, having several meanings. The word carries an evaluative dimension on only some of these meanings, while on others it does not. This suggestion has been developed by various authors. Corvino, for instance, distinguishes several senses in which homosexuality might be said to be unnatural, such as being uncommon or unconventional, violating an organ's principal purpose, etc. On all these meanings he finds the arguments that appeal to its unnaturalness uncompelling. This approach has also been taken in the literature that focuses on the use of such arguments in the controversy over the acceptability of food obtained from GMOs. In what follows I focus on this use of the argument more extensively, given that the discussion here is much more advanced than in other fields of philosophy in which such arguments are analyzed. After reviewing the literature on this topic, I develop my own answer to the question why appeals to nature in argumentation are problematic.

\section{The controversy over the use of genetically modified organ- isms in the food industry}

Ever since genetic engineering (GE, for short) technology has come to be used in the food industry, and food obtained from GMOs has been introduced in the markets in 1994, the topic has been surrounded by constant controversy. While there is consensus in the scientific literature that the currently available GM food does not pose a risk to health greater than food that is obtained from non-

\footnotetext{
${ }^{1}$ Moreover, if speakers systematically fail to capture the evaluative component of the meaning of the word, shouldn't we expect the word to end up losing this evaluative component? After all, meaning is determined by use. So why does "natural" still have this concealed evaluative meaning, despite its being systematically concealed from speakers?
}

(C) Andrei Moldovan. Informal Logic, Vol. 38, No. 3 (2018), pp. 409-437. 
GMOs, ${ }^{2}$ the public opinion is significantly divided. According to a recent study only $37 \%$ of the general public believe GM food is completely safe for consumption (Funk and Rainie 2015). Due to the campaigns of activists and NGOs who oppose genetic engineering (GE) technology, and who have made their views popular through mainstream media (Johnson 2013 p. 34), GM crops have achieved a particularly bad reputation. This is the case especially in Europe, as shown in Marris (2001) and Delwaide et al. (2015). According to Delwaide et al. (2015), who cite several editions of the Eurobarometer survey on Europeans' attitudes towards biotechnology, in 1991 $74 \%$ of the EU citizens agreed that GE research on plants should be encouraged, while by 2005 this percentage drops to 27\%. Most EU citizens in 2005 viewed GM food as risky, not useful and not morally acceptable, an attitude confirmed by the 2010 edition of the Eurobarometer on biotechnology. As a result, several countries have progressively banned the farming of GMO's, although these crops had previously been approved by the European Food Safety Authority of the EU (Scott-Thomas 2013). While informed skepticism can protect consumers and preserve the environment (Johnson 2013, p. 69), radical opposition to the GE technology has proven to be unwarranted, and prone to have severe consequences. ${ }^{3}$

One recurrent claim made by opponents of GM food is that genetic modification of an organism in the laboratory is unnatural. The perceived unnatural character of the process of obtaining GMOs and of the result itself is taken to support the claim that GMOs are either

\footnotetext{
${ }^{2}$ For instance, Nicolia et al. (2013) cataloged and analyzed 1783 studies on the health impact and environmental impact of GM crops published over the previous ten years. They conclude that "The scientific research conducted so far has not detected any significant hazards directly connected with the use of GE crops" (2013 p. 1) The claim is embraced by many official scientific organizations, including the US Society for Toxicology, the American Association for the Advancement of Science, The National Research Council (US) etc. (Acosta 2014). However, Nicolia et al. point out, the scientific debate on certain aspects of the GE technology "has frequently been distorted by the media and often used politically and inappropriately in anti-GE crops campaigns." (2013 p. 8)

${ }^{3}$ To give one such example, in September 2002 in the midst of a devastating food crisis in southern Africa, the government of Zambia refused to accept American donations because much of the food aid contained GM corn and soya, which the president of Zambia called "poison" (The Economist, Sept. 19" $9^{\text {th }}$ 2002).

(c) Andrei Moldovan. Informal Logic, Vol. 38, No. 3 (2018), pp. 409-437.
} 
unhealthy or unethical. Cooley, Goreham and Youngs (2004) report the result of a study the authors realized by interviewing people in relation to their opinion on the moral acceptability of GE technology. Many participants in the study express their worry about the longterm environmental effects of farming GMOs and invoke moral responsibilities that humans have towards the environment. In a different paper, Cooley and Goreham (2004: p. 47) call a particular form of argument that occurs with frequency in the body of data they collected the "Unnatural Is Unethical" argument. The authors' suggestion is that these arguments could be reconstructed as in (2) above, the result being (7):

7. Premise 1: GMOs (and GM food products) are unnatural objects.

Premise 2: Any unnatural object is morally bad.

Conclusion: GMOs (and GM food products) are morally bad.

However, I will not restrict the present discussion to appeals to nature that have an ethical dimension, but also consider similar appeals to nature where "morally bad" is replaced by other evaluative terms, such as "unsafe", "unhealthy", "bad for the environment", "bad solution to a particular problem" etc. The authors point out that the argument appears in two versions: one in reference to objects such as GMOs, and another in reference to the GE technology.

None of the participants in the study mentioned put forward a piece of text or dialogue that could be said to contain this argument explicitly. However, Cooley and Goreham's (2004) modus ponens scheme in (7) captures a basic inference that plays an important role in the argumentation, and which goes from $X$ is unnatural to $X$ is bad or $X$ is wrong. Here is one typical answer to questions related to GM food that the respondents in the study gave:

8. "Those $[\mathrm{GM}]$ genes were not there before. They are manmade genetic combinations, and since they weren't in the natural environment before, I view that as contamination." (Cooley, Goreham and Youngs 2004 p. 528)

To call something "contamination" is to imply that it is bad for the environment. The reason given in (8) why GMOs are bad for the 
environment is that "they weren't in the natural environment before", so an inference from unnatural to bad is being made.

A second version of the argument goes from calling traditional non-GMOs "natural" to concluding that they are healthy or good for the environment (i.e., in accordance with our responsibilities towards the environment). The argument structure, if we respect Cooley and Goreham's (2004) preferred reconstruction, is the following:

9. Premise 1: Traditional (non-GM) organisms (and non-GM products) are natural objects.

Premise 2: Any natural object is morally good.

Conclusion: Traditional (non-GM) organisms (and non-GM products) are morally good.

An organic farmer of non-GMOs praises "natural" ways of dealing with pests, as opposed to "external corrections", such as those achieved though GE techniques. He considers that the former are preferable because they are natural:

10. When I look at our organic farm it's a constant balancing act. When there is a pest problem, we look at the system that nature uses... Nature just has this wonderful way of constantly finding ways to correct things... For instance, when we go in and try to correct a problem with an external correction, often times we end up with bigger problems than what we started with. (Cooley, Goreham and Youngs 2004 p. 527)

The following text is from a different source, a commercial for food products obtained partly from GMOs:

11. The products of biotechnology will be based on nature's own methods. Monsanto scientists are working with nature to develop innovative products for farmers of today, and of the future. (Sagoff 2001 p. 4-5)

We can identify here the same inference captured in (9), the inference from "X is natural" to "X is good". As Sagoff (2001 p. 5) notes, arguments of this kind are put forward not only by the enemies of GMOs but by producers of GM food as well, in their effort to "give the consumer whatever he believes in" (Sagoff 2001 p. 5). Given the consumers' opinion that "natural" food is healthy, or heathier than 
"unnatural" food, GMOs are presented as the result of the scientists' work "with nature".

In some cases the appeal to nature is more subtle than the argument schemes presented in (7) and (9). The rejection of GMOs is sometimes rooted in a form of skepticism or distrust of technological advances. What is specifically objected to is the biochemical and biomechanical process of changing the genetic structure of a cell, and consequently, of a living organism born out of that cell; a process which is perceived to be potentially dangerous to humans and to the environment. The perception of risk might be supported by providing alleged evidence that such technologies are risky, and in that case the argumentation might enter into technical details. In other cases the claim that GE involves an important risk is supported by pseudoscientific beliefs (Wager 2014) that intentionally ignore and contradict scientific knowledge while being deeply problematic. Here is one example from an on-line magazine article:

12.GMOs are awful for so many reasons, but the biggest being that they are NOT natural! They are man-made, toxic products the human body is not made to consume and digest. (Jo 2013)

In many cases, the perception of risk is based on a general distrust of technological advances, especially very novel ones, which are considered by many to be insufficiently safe, in comparison to more traditional techniques which are thought to have passed the test of time. This argument is not in itself an appeal to nature, but an appeal to nature might enter the scene when the potential danger of GE technology is supported by invoking its artificial and "unnatural" character, the result of human activity, and so, fallible and unpredictable. The argumentation in the following passage gets close enough to this pattern:

13. In order to survive, the organism needs to engage in natural genetic modification... That is why organisms and ecosystems are particularly vulnerable to the crude, artificial GM RNA and DNA created by human genetic engineers. It is also why genetic modification can probably never be safe. (Ho 2013, emphasis added)

In the academic literature devoted to the analysis of appeals to nature in the public controversy over the acceptability of GMOs it 
has been suggested that in order to analyse these different appeals to nature one must have a better understanding of the precise meaning that is assigned to "nature" and "natural", and of what conception of nature is at play in these arguments. Several senses of the word "nature" and its derivations have been identified. Various authors argue that these words are ambiguous, having various meanings, and that the evaluation of the argument varies considerably depending on which meaning we ascribe to the word (Cooley and Goreham 2004; Rozin 2005; Sagoff 2001; Siipi 2013; Siipi 2015; Verhoog et al. 2003). I briefly discuss below several definitions of these words considered in this literature.

\section{The meanings of "natural"}

Some of the references concerning the meaning of "natural" in the literature go back to John Stuart Mill (1906), who pointed out that, on one particular use, the word "means the sum of all phenomena, together with the causes which produce them; including not only all that happens, but all that is capable of happening" (Mill 1904 p. 7). In this sense, what is not natural is supernatural, i.e., a phenomenon that does not abide by the laws of nature. If this is the sense ascribed to "natural" and "unnatural" in (9) and (7) respectively, then the arguments fail to offer any intuitive support for their conclusions. In particular, argument (11) has a false first premise, as GMOs are as natural as non-GMOs. None of them are produced by supernatural means. In contrast, (9) has a false second premise: something is not good just because it is part of nature, in this very wide sense of the term. This does not mean that the arguments are fallacies, because the reason why the arguments are bad is not a logical one. They are valid arguments each with a false premise.

Siipi (2015 p. 808) and Cooley and Goreham (2004 p. 49) point out that it is a mistake to assume that this is the only possible sense of the word and to reject appeals to nature on this basis. A second definition of "natural" that Mill considers refers to "what takes place without the agency, or without the voluntary and intentional agency, of man." (1904 p. 9) In this sense, "unnatural" means artificial, cultural, or the product of human activity. More closely related to the debate about GMOs, "natural species" would be species or varieties 
of plants and animals existing prior to man's intervention and prior to the application of technology. ${ }^{4}$ This is the meaning of natural that could be assigned to some of the appeals to nature presented above, arguably in cases (8) and (10), and definitely in (13), where natural genetic modification is contrasted with artificial genetic modification.

On this definition of "natural" the arguments are not much better than on the previous definition considered. The first premise of (7) is true (that is, GMOs are unnatural), but the first premise of (9) (which says that non-GMOs are natural) is false. Virtually all organisms that humans farm, both those obtained through GE technology and those that are not, are the result of a complex process of transformation through human intervention. Traditional non-GM crops are the result of a long historical process of selection and interbreeding. So, one could argue equally well that both GMOs and nonGMOs are unnatural and bad for that matter. However, as Siipi (2015 p. 810) notes, if we see the distinction between natural and unnatural as a continuous gradient instead of a distinction between two clearcut concepts, then it is possible to see GMOs as more unnatural than their non-GM counterparts. But, she explains, matters are not straightforward here either: some varieties of GMOs receive less human intervention during the process of farming, for instance, they require no pesticides, which makes them more natural (at least in that respect) than non-GMOs that do require pesticides.

The problems with the two arguments do not stop here, as the second premise of each argument is also deeply problematic. Not everything that is natural is morally good (as the second premise of (9) asserts), or good in some other sense (Siipi 2015 p. 810-811). A hurricane that kills many is natural, but we would not say that it is morally good (or bad, for that matter), that it is desirable, healthy, etc. On the other hand, not everything that is unnatural is bad (as the second premise of (7) says), unless we are willing to accept that all products that require technological intervention are morally bad. However, notice that some of the appeals to nature presented above rely on the (sometimes implicit) premise that whatever is natural is

\footnotetext{
${ }^{4}$ This suggestion is due to an anonymous referee for this journal. 
better than what is artificial, either in the sense of being better for the environment (as in example (10)), or in the sense of being safer for humans (as in example (13)). That is, the proponents of these arguments might allow that not everything that is natural is good, and not everything that is unnatural is bad, but might insist that the former has certain comparative advantages relative to the latter. But why would one believe without specific evidence that, for a particular case such as food crops, the more natural alternative (of interbreeding and selection) is preferable to the more artificial one (GE technology)? The explanation seems to be that, at least in some cases, arguers have an idealized conception of nature as intrinsically balanced and wise (as it seems to be the case of the arguer in example (10)). This might motivate the view that traditional techniques of obtaining new crops are preferable to novel technologies, because the former ones are thought to rely on nature's own ways of behaving, and so, to be stable, safe and predictable. In other cases this belief might be based on a complex religious and mystical conception of nature, which is thought to be kind and benignant to humans if they respect her and do not use aggressive technology, as GE technology is thought to be. Bioethicist Paul B. Thompson (2000) says this is "not exactly a religious view, because it's not something they would have learned in church. It's quasi-religious, because it's a particular way of thinking about nature that's not in the direction that science has gone." However, traditional religions might also promote this idealized view of nature. Sagoff (2001 p. 5) thinks that this, in fact, corresponds to a different meaning that the word "nature" receives, as "Creation in the sense of what God has made."

The third meaning that Mill discusses is deployed when we talk of the nature of a particular object or action, where "nature" refers to "the ensemble or aggregate of its powers or properties" (Mill 1904

\footnotetext{
5 Torres (2018: 19) discusses various examples of appeals to nature put forward by arguers who oppose vaccination, and who support their claims on such a conception of nature. Radical rejection of vaccination is associated with the New Age cultural movement. This promotes a cluster of religious and mystical ideas, including a "holistic" view of nature, which receives certain human traits: she is kind, balanced, wise, safe for those who respect her etc. This view motivates a rejection of modern technology and of mainstream science, and a preference for alternative and traditional approaches to healthcare.
}

(c) Andrei Moldovan. Informal Logic, Vol. 38, No. 3 (2018), pp. 409-437. 
p. 7). In this sense, the word refers to a relational property, as it relates an object with a property that is said to be part of the nature of that object. This sense is sometimes deployed in debates about the nutritional suitability of certain kinds of food, as when it is claimed that humans are "natural herbivores", and not "natural carnivores" (Siipi 2015 p. 811). For instance, the World Health Organization gives the following advice on its page:

14. Breast milk is the natural first food for babies, it provides all the energy and nutrients that the infant needs for the first months of life... (emphasis added) ${ }^{6}$

The word "natural" in (9) and "unnatural" in (7) could be taken in this sense, as referring to the nutritional suitability of food produced from GMOs. If a kind of food is not completely fit for human consumption and might prove detrimental to health, there are moral reasons to reject it. And the first premise of (7), on this interpretation, asserts that food obtained from GMOs is not appropriate to be consumed by humans. This is an empirical claim that proponents of the argument need to establish. While GE technology is no guarantee of nutritional suitability, there is no good reason to think that GM food available on the market is unsuitable for human consumption, according to the scientific literature reviewed above (see fn. 2). In fact, this literature suggests quite the contrary.

A fourth sense of "natural" that Siipi (2015 p. 812) identifies refers to the ecological suitability, in the sense of the suitability of an environment for an organism, or of the organism for the environment. The desert is not the natural habitat of the shark, but the ocean is. An invasive species is unnatural in the sense that it is not suitable for the environment it invades, and it damages it. Opponents of GM crops usually perceive them as unsuitable for the environment in which they are planted, and in this sense, unnatural. Again, the scientific literature reviewed indicates that there is no reason to think so of GMOs in general, although this could be the case for some GMOs.

\footnotetext{
${ }^{6}$ Source: http://www.who.int/nutrition/topics/exclusive_breastfeeding/en/, consulted on 05.08.2018. I thank an anonymous referee for this example.
}

(C) Andrei Moldovan. Informal Logic, Vol. 38, No. 3 (2018), pp. 409-437. 
A fifth sense of "natural" is equivalent to "that which is authentic or true to itself", the opposite of "the specious, illusory, or superficial. The "natural" is trustworthy and honest, while the sophisticated, worldly, or contrived is deceptive and risky." (Sagoff 2001 p. 5) In this sense "natural vanilla" is opposed to "substitute vanilla", "imitation of vanilla", of "synthetically obtained vanilla" (Siipi 2012 p. 12).

A sixth sense, identified in Cooley and Goreham (2004 p. 51), refers to "an uncommon or abnormal object." They note that the first premise of (7) is true on this reading, given that GMOs are uncommon when considered relative to all organisms that have existed or exist. However, the second premise of the argument is unacceptable, because many rare actions or things are morally valuable (e.g., supererogatory actions), and many common ones are not (e.g., pain).

A seventh sense identified in the literature is that of "naturalness as familiarity" (Siipi 2012 p. 12). And the counting could go on.

\section{The evaluation of the argument}

To sum up, most contributors to the debate I have presented conclude that an appeal to the unnatural character of GMOs is a bad argument on most of the senses of the word. ${ }^{7}$ The authors mentioned do not identify here a fallacy of appeal to nature, given that the argument does not fail on a logical dimension of evaluation, but because it turns out to have at least one false or unacceptable premise on most of the readings. What is more controversial is whether the argument is bad on all of these senses. Some authors think so. For instance, Cooley and Goreham (2004 p. 54) conclude that "if we truly desire

\footnotetext{
${ }^{7}$ A further problem with some of these interpretations is that the resulting argument might instantiate the naturalistic fallacy (Thomason 1997 p. 64). The naturalistic fallacy does not necessarily involve an explicit reference to nature, but an inference from what is the case to what ought to be the case. The question then becomes whether "natural" has a normative or evaluative dimension. If it does this fallacy is not committed. On some of the disambiguations of "nature" discussed above the word might have a normative dimension, so the naturalistic fallacy is not committed. On others, it does not, so the naturalistic fallacy might be instantiated. However, according to my proposal, the main problem with most appeals to nature is a different one, as I explain below.
}

(c) Andrei Moldovan. Informal Logic, Vol. 38, No. 3 (2018), pp. 409-437. 
to make headway with the moral issue of transgenic organisms, we might have to stop spending time on UIU [i.e., Unnatural is Unethical argument] and seek a better argument." However, others suggest a different conclusion. Siipi (2015 p. 813) and Sagoff (2001 p. 5) take the various senses of "natural" identified to be logically independent of one another. This observation is used to argue that, even if the argument fails when the word is taken in one sense, it need not fail when it is understood in another sense. Siipi (2012 p. 12-13) argues that some senses of "natural" are conceptually connected to the healthiness of food: for instance, naturalness as authenticity (in contrast to food substitutes), or naturalness as familiarity (in contrast to unfamiliar products):

Thus, consumers' desires for natural food and appeals on the naturalness of food should not be ignored as fundamentally senseless and irrelevant. Nevertheless, not all naturalness claims are unproblematic and, thus, a good naturalness argument or appeal on naturalness should contain an explanation of the sense in which the term is used. (2012 p. 12-13)

In the same line, Verhoog et al. (2003) point out that "the argument from (un)naturalness" is dismissed as "little more than sentiment and confusion" after considering only the first two senses of the word. They suggest that there are other possible senses of the word that we need to take into consideration. In particular, "natural as related to the realm of life and life processes (the organic)" (2003 p. 46) might provide a satisfactory interpretation of the argument. However, they add that "an explication of the concept of nature and the (un)natural within organic agriculture is urgently needed, if only to prove that there is more at stake than just sentiment and confused ways of argumentation." (Verhoog 2003 p. 31)

I do not claim that appeals to the unnaturalness of GMOs are bad arguments on all possible interpretations (although, the above analysis shows that they are bad arguments on most salient interpretations of the word). I allow for the possibility that there might be an interpretation on which the argument has a certain force, and I agree with Siipi (2012) and Verhoog (2003) that the search for a clearer definition of naturalness is indeed a legitimate aim. However, finding this possible meaning would ultimately be, at least in some cases, 
the result of conceptual creation, rather than conceptual analysis of a pre-existing use of the word. The question whether a clearer concept of "nature" is possible and the question about the correct interpretation of the word as it actually occurs in real-life contexts are two very different theoretical desiderata. The above quotes from Siipi (2012) and Verhoog et al. (2003) seem to move from one kind of considerations to the other without particular care. I am interested here in the analysis of appeals to nature, and not in designing a concept of nature on which the argument becomes compelling.

In the order of analysis, my claim is that "natural", as it actually occurs in some appeals to nature, lacks a clear, identifiable meaning. This suggestion is not meant as an alternative to the analysis and evaluation presented so far, but rather as an additional complication that needs to be considered when evaluating arguments that appeal to nature. The various interpretations of "nature" and "natural" that were identified in the literature are all possible meanings of any utterance of these words. But it is not the case that any utterance automatically receives one meaning or another of the various possible ones. Some conditions have to be fulfilled in order for the utterance of a word to carry a particular meaning. The idea, in a nutshell, is that a word must be used with a particular communicative intention to express one sense among the various possible ones. I support my claim by relying on semantic externalism, a widely accepted conception of the mechanisms by which words acquire their meanings when we use them.

\section{Semantic externalism, meanings, and intentions}

Why do the words we utter mean what they mean? One widely accepted answer to this question is found in semantic externalism. Saul Kripke formulates it for the particular case of proper name, for which, he argues, three conditions need to be fulfilled in order for the use of the proper name (e.g., my utterance of "Tristan Tzara") to have a particular referent: (C1) there must be a successful initial baptism, by which the name is associated to a particular individual, and which is usually performed by ostention; (C2) a chain of uses of the name must develop over time and preserve the reference; and (C3) new users can hook up to the chain by using the name with the

(c) Andrei Moldovan. Informal Logic, Vol. 38, No. 3 (2018), pp. 409-437. 
intention to refer to whatever or whoever is the referent of the name in that particular linguistic community. The requirement condition (C3) introduces is that of forming what is sometimes called a "deferential intention".

Given that these three conditions are sufficient for successful deference, it follows that semantic externalism does not require for correct use of the name that the speaker have accurate descriptive knowledge of the referent. She might fail to identify the individual referred to in many habitual or less habitual situations. In fact, she might be grossly mistaken about who the referent of the name is. For instance, I might falsely believe that Tristan Tzara is one of Santa Clause's reindeers. When I utter the sentence "Tristan Tzara is one of Santa Clause's reindeers" what I say is meaningful and false precisely because I manage to refer to Tristan Tzara by my use of the name, and not to a reindeer or anything else.

Kripke (1980), Putnam (1975), Devitt (1981), and others extend these meta-semantic considerations to natural kind terms such as "water" and terms for physical magnitudes such as "temperature". The extension of these terms is fixed by mechanisms that have a social and historical dimension, in ways that are analogous in important respects with the case of proper names. As in the case of proper names, linguistic competence with these terms does not require possessing knowledge of the essential properties of these substances or phenomena. Consider the word "water" and assume for the sake of the argument that having the chemical structure $\mathrm{H}_{2} \mathrm{O}$ is a necessary and sufficient property for a substance to be water. It is a historical truth that the chemical composition of water was not known for a long time to anyone in the linguistic communities that used "water" (or an alternative word) to refer to this substance. These people did possess some criteria for identifying water in normal contexts, but these criteria appeal to non-essential properties, and are neither necessary not sufficient for identification of water across all possible situations, as Kripke (1980) and Putnam (1975) argue. In other words, meaning is not in the head: linguistic competence with proper names and natural kind terms does not require having a uniquely identifying description of the essential properties of the referents. Users do not possess a definition (in the strict sense of the 
term) of water, and they need not possess one in order to use the word with its meaning. ${ }^{8}$ Linguistic competence also does not require access to the relevant social facts on which the meaning of the expression depends either: when or where the initial baptism took place, or how exactly the word was introduced in the language.

But then what does linguistic competence require from the speaker? It requires that the speaker rely on the community of competent language users that engage in the linguistic practice on which the meaning of the expression depends. In order to do so, he must form the deferential intention mentioned in condition (C3) formulated above. In Kripke's own words, for the case of proper names: "When the name is 'passed from link to link', the receiver of the name must, I think, intend when he learns it to use it with the same reference as the man from whom he heard it." (Kripke 1980 p. 96)

The externalist considerations about meaning are not limited to proper names and natural kind terms. Kripke and Putnam set the basis for a socio-historical theory of linguistic meaning in general, and not only of reference. Tyler Burge (1989 p. 283) extends the externalist thesis for a larger class of expressions applicable to empirical objects, stuffs, properties, and events. These include words for natural kinds such as "tiger", "water", "mud", "stone", "tree", but also artificial kinds such as "bread", "knife", "chair", "edge", "baby", "walk", "fight". In the same line, Gareth Evans (1982) notes that the general idea is that "individual speakers exploit general practices". He formulates the following "general principle":

If a speaker uses a word with the manifest intention to participate in such-and-such a practice, in which the word is used with such and such semantic properties, then the word, as used by him, will possess just those semantic properties. This principle has as much application to the use by speakers of words like "agronomist", "monetarism" as the like as to their use of proper names. (Evans 1982 p. 387)

Having the right deferential intention allows one to use an expression-form with the meaning it has in the linguistic community to which one defers. ${ }^{9}$ In David Kaplan's terms, it allows one to be a

\footnotetext{
${ }^{8}$ In fact, there is no such definition, in the sense of a true analytic a priori sentence.

${ }^{9}$ Donnellan (1993 p. 163) notes that we need to distinguish semantic deference from epistemic deference. The latter consists in deferring to an expert, or to a (c) Andrei Moldovan. Informal Logic, Vol. 38, No. 3 (2018), pp. 409-437.
} 
"language consumer" (1989 p. 602). As Kaplan notes, "Words come to us prepackaged with a semantic value. If we are to use those words, the words we have received, the words of our linguistic community, then we must defer to their meaning." (Kaplan 1989 p. 602) Thus, when I utter "Tristan Tzara", "water", "arthritis", "carburetor", or "nature" and "natural", for that matter, with the right deferential intention to mean whatever is meant by the word in the linguistic community, I manage to use these words with the meaning they have. This deferential intention is normally present whenever we use words and assume they have a meaning in the language, even when the deferential intention is formed by default, without being explicitly and consciously entertained.

As already mentioned, forming the deferential intention to participate in a particular linguistic practice is a necessary condition for successful deference, i.e., for being a consumer of a language. If the deferential intention is a necessary condition for a speaker's use of a word to have the customary meaning it has in a linguistic community, then the following thesis must be correct: if a speaker $S$ uses a word $W$ without the manifest intention to participate in a particular linguistic practice $P$ in which $W$ has a certain linguistic meaning, her use of $W$ does not acquire that linguistic meaning from the practice $P$.

To say that S's use of $\mathrm{W}$ does not acquire a particular linguistic meaning from a practice $\mathrm{P}$ is not yet to say that this use of $\mathrm{W}$ is meaningless. $\mathrm{S}$ might assign to $\mathrm{W}$ a new linguistic meaning by way of an explicit stipulation. In this case, $\mathrm{S}$ counts as a producer, and not a language consumer, in Kaplan's (1989 p. 602) terminology. However, if $\mathrm{S}$ is not a producer, and at the same time, fails to be a successful consumer of $\mathrm{W}$, we do have evidence that the use of $\mathrm{W}$ on behalf of $\mathrm{S}$ is semantically deficient.

community of experts, for the justification of a claim. Given that I have an incomplete mastery of the word "arthritis", and I do not possess necessary and sufficient criteria of identification of arthritis, I defer semantically to the community of medical experts for the exact meaning and correct use of the term. On the other hand, in uttering the sentence "I do not have arthritis" I may defer, epistemically this time, to the physician that gave me this diagnosis, as I lack direct evidence for this claim. If the physician is wrong about my condition my utterance is false, but still meaningful, in virtue of having deferred semantically.

(C) Andrei Moldovan. Informal Logic, Vol. 38, No. 3 (2018), pp. 409-437. 
Now, failed deference might occur for different reasons. Herman Cappelen (2013: p. 42) identifies one way in which uses of words might fail to fulfill the deference requirement. Cappelen proposes the following "strategy for how to discover nonsense", a strategy for identifying a potentially meaningless use of an expression if:

(i) The speaker is a member of a number of distinct subcommunities in which E is used in significantly different ways; (ii) The speaker is unaware of (i); and (iii) The speaker defers to the use it has in 'the community' without any particular subcommunity in mind and with (broadly speaking) causal connection to a multiplicity of communities. (2013 p. 42)

Talk of subcommunities should be understood here as referring to different linguistic practices of using the word in different ways, and with different meanings, even if the community, as a set of language users, is the same. If the speaker fails to identify a particular use of the word among the various ones that a word might have and merely defers to whatever or whoever is meant by the word, her deferential intention will not be successful. Consider, for instance, the case of someone who seriously utters the assertive sentence "Alexandre Dumas wrote Camellias and died in 1870", without realizing that there are two writers with this name, Alexandre Dumas the father, who died in 1870, and Alexandre Dumas the son, who wrote Camellias. Is what she said true or false? On both disambiguations of the name the utterance of the sentence is false. Still, intuitively we would not say that what the speaker said is false, as long we know the speaker assumes there is only one writer with that name. We would say that she failed to refer to any particular person. Indeed, there are two naming practices of using "Alexandre Dumas", and the speaker fails to realize this. The three conditions for failed deference that Cappelen (2013) proposes are fulfilled, and so Cappelen's account offers an explanation of the intuition that the speaker fails to refer to any one of the two writers. As a result, the utterance of the sentence does not express a proposition and does not have determinate truth-conditions.

\section{Appeals to nature and failed deference}

The above discussion provides us with insights into the analysis of (c) Andrei Moldovan. Informal Logic, Vol. 38, No. 3 (2018), pp. 409-437. 
arguments which contain appeals to nature. If we accept semantic externalism, at least two lessons can be drawn about how "natural" is used in these arguments. ${ }^{10}$ One lesson is that the speaker needs not entertain consciously, or even be able to provide upon request, a definition for her use of the word. The fact that arguers do not have a definition in their minds is not in itself a reason to reject the use of the word as confused or meaningless, as long as there is a particular linguistic practice that the arguer is relying on. As in the case of the use of "carburetor" that Donnellan (1993 p. 162) discusses, the speaker might lack the capacity to offer exact criteria for the correct use of "natural" according to a particular definition. Her use of the word is clearly individuated if she relies on the criteria of application of the word inherent to an existing linguistic practice.

The second lesson is that for successful deference to a particular use of the word "natural" - any of the various possible uses of the word - the arguer must have the manifest intention to use it in that particular way. This does not mean that the arguer should put forward an explicit definition of the word or give examples of its correct use. However, it does require being able to identify a particular linguistic practice and distinguish it from others. But, as in the case of "Alexandre Dumas" discussed, in many cases of the use of "natural" and related terms arguers do not seem to distinguish between the various possible meanings, in accordance with one or the other of the various existing definitions discussed above. In many cases arguers do not even consider the possibility of there being several possible meanings of the word. In other words, conditions (i) to (iii) that Cappelen outlines are fulfilled: there are different uses of the word

\footnotetext{
${ }^{10}$ The above discussion of semantic externalism focuses on proper names and common nouns, and not on adjectives such as "natural". An anonymous referee suggests this might be a potential problem for the account presented here. However, notice that some appeals to nature, such as examples (8) and (9) above, use the common noun "nature", instead of the adjective "natural". More importantly, for authors such as Gareth Evans (1982), quoted above, and Joseph Almog (1984) externalist considerations set the basis for a general theory of how individual speakers exploit linguistic practices, and so the externalist considerations are applicable to all expressions, including adjectives such as "natural" and "unnatural". For a general, and much more detailed, introduction to semantic externalism see Wikforss (2008).
}

(c) Andrei Moldovan. Informal Logic, Vol. 38, No. 3 (2018), pp. 409-437. 
that the speaker does not distinguish, and merely defers implicitly to whatever the word means in the linguistic community. Good candidates for a use of "natural" and "nature" where the arguer fails to identify and choose a particular meaning is example (11) (the advertisement which reads that "The products of biotechnology will be based on nature's own methods."), example (3) (Gwyneth Paltrow's claim that "I don't think anything that is natural can be bad for you."), and (4) (Angie and Debbie Winans' song about homosexuality, which says "It's not natural").

The thesis that I am advancing is not that the word "natural" is itself meaningless, or that all the uses of the word are. The discussion in the fourth section suggests that the word has a variety of meanings, some of them being logically independent of others. The word itself is arguably ambiguous, having different unrelated meanings, and also some closely related ones. An utterance of "natural" has a determinate meaning when the word is used with the intention to conform to one of the definitions mentioned above. In some cases, such as (8), (10) and definitely (13), these words are used with a clear deferential intention, and the larger linguistic contexts in which the arguments occur makes this clear (as discussed in section 4 above). ${ }^{11}$

Concerning the cases of failed deference, a possible objection to my proposal could be the following: a charitable interpretation, it might be said, should always and by default favour the meaning (or meanings) on which the argument turns out to be stronger. After all, this is what several participants in the debate suggest we should do (Siipi 2013, Verhoog et al. 2003). They argue that we should check whether arguments (7) and (9) are good on any one of the various possible senses of the word and choose that interpretation on which

\footnotetext{
${ }^{11}$ Another example of this kind is the use of "nature" in the academic debate in the field of environmental philosophy about the value of restoration of ecosystems intentionally destroyed for the purpose by mining or other industrial activities. Elliot (1982: 383) develops and discusses the environmentalist argument that "an area is valuable, partly, because it is a natural area, one that has not been modified by human hand." This is a clear appeal to nature, but it does not suffer from an underdetermination of meaning, given that the author makes clear throughout the paper that by "nature" he means environments that have not been modified by human intervention. Elliot's paper argues that such appeals to nature are good arguments, and that pristine nature has an intrinsic value. I thank an anonymous referee for the reference.
}

(c) Andrei Moldovan. Informal Logic, Vol. 38, No. 3 (2018), pp. 409-437. 
they are. Arguably, charity requires that we prefer the interpretation that makes most of the utterances true and the arguments as strong as possible (unless the speaker explicitly disavows that interpretation). But I think this reply will not do. The general considerations pertaining to the externalist account of meaning that I introduced in the previous sections indicate that an utterance of a word receives a meaning only when certain conditions are fulfilled. In particular, the speaker must identify a particular linguistic practice among the various existing ones and manifest her intention to use the word in accordance with the norms that are constituent of that practice. When it is safe to assume that the speaker does not distinguish the various linguistic practices and does not have a particular one in mind (as in the example of "Alexandre Dumas" discussed above), the necessary conditions for successful deference are not fulfilled. Charity cannot provide for the necessary facts that need to be given in order for deference to be successful. I take it that considerations of charity are applicable only in those cases in which we have good reasons to believe the speaker does have the intention to use the word in accordance to one particular linguistic practice, only that we cannot tell exactly which one. Such considerations are not applicable when we have no reason to believe the speaker distinguishes the various linguistic practices.

A second objection to the present account, suggested by an anonymous referee, might be formulated as follows: the account leaves out cases in which an arguer intentionally uses words in a loose manner, without having a specific meaning in mind. As the referee points out, "ideographs" is the term coined in rhetoric studies for such words. McGee (1980) characterizes them as follows: "An ideograph is an ordinary language term found in political discourse. It is a high-order abstraction representing a collective commitment to a particular but equivocal and ill-defined normative goal." (1980: p. 15) McGee writes that they are "slogan-like terms", and gives as examples "democracy", "equality", and "property". Some of the loose uses of "natural", although not a political term, fit well in this category. These words tend to have a significant argumentative impact on audiences precisely because their use is loose and they have multiple interpretations. Their use in argumentation conveys a message 
that every audience can interpret in his or her preferred way, and so, it is a potential means of gaining the adherence of many audiences. "Natural" might be purposely used in this manner in advertising and in the rhetoric of anti-GE advocates. But then, the referee's objection goes, it is not meaningless at all.

Two points need to be made in reply. First, in cases in which "natural" and "unnatural" are used in a loose way on purpose, as a strategical movement in argumentation, failure of deference does not seem to be the best characterization of what is going on. Instead, we might want to talk about a refusal to defer to a particular linguistic practice. Second, I agree that "natural", even in cases of failed deference, is not a completely meaningless word. It does make a certain contribution to the conversation, if not semantic then at least pragmatic. I also agree that it could be classified as an ideograph. But notice that McGee considers such terms as "ill-defined". My claim is that the lack of successful deference results in a form of semantic underdetermination of the word. Paying attention to the requirement of semantic deference and the mechanism by which it is achieved by language consumers indicates the way in which the use of a word might be deficient, and its meaning underdetermined. Such a diagnosis is relevant to argument interpretation and reconstruction.

Several authors quoted above make similar suggestions. Siipi (2015) does not reject the word as meaningless, but comments that "the senses of the "natural" are often mixed and confused... The term "natural" is often used without specifying the intended meaning." (2015 p. 813). I have argued that in those cases in which there are reasons to think the arguer is not aware of the various possible meanings of "natural" and does not intend to use the word with a particular meaning of the various existing ones, the word fails to carry a determinate meaning. ${ }^{1213}$ In his discussion of the use of

\footnotetext{
${ }^{12}$ Also Thompson (2000) writes: "even people who label foods as unnatural don't always have an exact explanation for why they think the way they do."

${ }^{13}$ This conclusion is also an intuitive one: as one newspaper article put it, " $66 \%$ of consumers wrongly think "natural" means something" (USA Today, June 17, 2014): "Two-thirds of Americans think the world "natural" on the label of a packaged or processed food means it contains no artificial ingredients, pesticides or genetically engineered organisms, a survey released this week by the magazine Consumer Reports found... The problem is, consumers are wrong." The presence (c) Andrei Moldovan. Informal Logic, Vol. 38, No. 3 (2018), pp. 409-437.
} 
appeals to the unnaturalness of homosexuality as an argument to reject it, Corvino also concludes that the word "is simply a term of abuse, a fancy word for "disgusting," a way to mask visceral reactions as well-considered moral judgments." (2013: p. 97) He also comments that "unnatural" "appears to be nothing more than a rhetorical flourish, invoked to smear things that the speaker finds abhorrent." (2013: p. 79) These considerations all coincide with the thesis I have argued for here.

In conclusion, the problem I have identified in many appeals to nature (although not all) is a semantic one and consists in a failure to defer to a particular linguistic practice in which the word "natural" receives a definite meaning. ${ }^{14}$ In turn, this suggests a further question: is failure of deference in appeals to nature to be classified as a fallacy? When "natural" and related words do not have a determinate meaning, do we have a "fallacy of appeal to nature"? The terminology of fallacy might be at times a barrier in the way of a more nuanced analysis of arguments, as it suggests a clear-cut division between two kinds of arguments: fallacious ones and non-fallacious ones (i.e., bad and good). In fact, things are more complex: some arguments may possess certain undesirable features that we might want to avoid.

Douglas Walton raises a similar question concerning whether unclarity in argumentation is in itself a fallacy. His answer is that unclarity "in itself is more of a failure (or blunder) of communication than a fallacy." (1996 p. 176) But he comments that unclarity might turn into a fallacy when it is purposefully used to gain the adherence

of "natural" on food labels does not mean this, and it does not actually have any specific meaning. The article goes on to explain that the U.S. Food and Drug Administration decided not to define the term "natural" or to prohibit its use on food products on the basis that such prohibition would be an unconstitutional restriction on free speech.

${ }^{14}$ Apart from "natural", another word that is often used without clear deferential intentions is "energy", which Marianne Doury (1997) discusses in relation to pseudoscientific contexts. Her conclusions go in the same direction as the one I have reached here, i.e. that such words are used without a determinate meaning: "Que faut-il entendre exactement par énergie? Rien de précis... il est souvent difficile de savoir de quelle acception relèvent les différentes occurrences du mot énergie dans le discours des parascientifiques." (1997 p. 220)

(C) Andrei Moldovan. Informal Logic, Vol. 38, No. 3 (2018), pp. 409-437. 
of the audience by arguments that might seem better than they actually are due to the false appearance of clarity. This conclusion seems warranted here as well: the problem I have identified for some uses of "natural" is not a logical one, but a semantic one. It does not concern the relation between the premises and the conclusion of the argument. Instead, it occurs at a previous level, that of interpretation and reconstruction. However, in line with Walton's suggestion, we could see a fallacy in those cases in which unsuccessful deference has the effect of creating the impression of a better argument than it actually is. This is in accordance with classical definitions of fallacies, such as Hansen's: "a fallacy is an argument that appears to be a better argument of its kind than it really is." (Hansen 2002, p. 152) Arguably, this is precisely what is going on in example (11) discussed above. In this sense, appeals to nature might be fallacious when the semantic deficiency in the use of "natural" passes unobserved and unchallenged, but helps create the impression of a good argument. The apparent force of such appeals to nature fades away when one stops to consider the various possible meanings of "nature" and "natural".

Acknowledgements: The research that led to this paper has been supported by the Spanish Ministry of Economy and Competitiveness, EXCELENCIA program, project no. FFI2016-79317-P, "El acto de habla de argumentar y su lugar en la Teoría de la argumentación". Special thanks to Obdulia Torres and to two anonymous referees for this journal for their valuable comments and suggestions.

\section{References}

Acosta, Luis. 2014. Restrictions on Genetically Modified Organisms:

United States, Library of Congress, http://www.loc.gov/law/help/restrictions-on-gmos/usa.php\#Opinion Retrieved 26.08.2017

Almog, Joseph. 1984. Semantical Anthropology. Midwest Studies in Philosophy 9 (1): 478-489.

Burge, Tyler. 1989. Wherein is language social? In: Reflections on Chomsky, ed. Alexander George. Oxford: Blackwell: 175-191. Repr. 
in: Burge, Tyler. 2007. Foundations of Mind: Philosophical Essays, Vol. 2, 275-290. Oxford: Oxford University Press.

Cappelen, Herman. 2013. Nonsense and illusions of thought. Philosophical Perspectives, 27 (1): 22-50.

Cooley, D. R. and G. A. Goreham. 2004. Are Transgenic Organisms Unnatural? Ethics and the Environment 9(1): 46-55.

Cooley, D.R., G. A. Goreham, and George A. Youngs, Jr. 2004. Practical Moral Codes in the Transgenic Organism Debate. Journal of Agriculture and Environmental Ethics 17: 517-544.

Delwaide, Anne-Cécile, Lawton L. Nalley, Bruce L. Dixon, Diana M. Danforth, Rodolfo M. Nayga Jr., Ellen J. Van Loo, and Wim Verbeke. 2015. Revisitins GMOs: Are There Differences in European Consumers' Acceptabe and Valuation of Cisgenetically vs Transgenetically Bred Rice? PLoS One 10(5): 14.

Devitt, Michael. 1981. Designation. New York: Columbia University Press.

Donnellan, Keith. S. 1993. There is a word for that kind of thing: An investigation of two thought experiments. Philosophical Perspectives 7: $155-171$.

Doury, Marianne. 1997. Le débat immobile. L'argumentation dans le débat médiatique sur les parasciences. Editions Kimé.

Elliot, Robert. 1982. Faking Nature. Inquiry vol 25: 81-93.

Evans, Gareth. 1982. The Varieties of Reference. Oxford: Oxford University Press.

Funk, Cary and Lee Rainie. 2015. Public and Scientists' Views on Science and Society. Pew Research Center.

http://www.pewinternet.org/2015/01/29/public-and-scientists-viewson-science-and-society/ Retrieved 26.08.2017.

Hansen, Hans Vilhelm. 2002. The Straw Thing of Fallacy Theory: The Standard Definition of "Fallacy". Argumentation 16 (2):133-155.

Ho, Mae-Wan. 2013. Why GMOs Can Never Be Safe. Dr. Mercola's Natural Health Newsletter.

https://articles.mercola.com/sites/articles/archive/2013/08/06/geneticmodification.aspx Retrieved 7.08.2018 
Jo, Amanda. 2013. GMO Foods Are Killing Us. Elite Daily. https://www.elitedaily.com/life/gmos-are-killing-us Retrieved 7.08.2018

Johnson, Susan. 2014. Genetically Modified Food: A Golden Opportunity? Sustainable Development Law \& Policy 14(1): 34, 6970.

Kaplan, David. 1989. Demonstratives. In Joseph Almog, John Perry \& Howard Wettstein (eds.), Themes From Kaplan. Oxford University Press. pp. 481-563.

Kripke, Saul. 1980. Naming and Necessity. Cambridge MA: Harvard University Press.

Marris, Claire. 2001. Public views on GMOs: deconstructing the myths. Stakeholders in the GMO debate often describe public opinion as irrational. But do they really understand the public?. EMBO Reports. 2 (7): 545-8.

\section{http://embor.embopress.org/content/2/7/545}

McGee, Michael Calvin. 1980. The "ideograph": A link between rhetoric and ideology. Quarterly Journal of Speech. 66(1): 1-16.

Mill, John Stuart. 1904. On Nature. In Nature, The Utility of Religion and Theism. Watts \& Co. for the Rationalist Press.

Nicolia, Alessandro, Alberto Manzo, Fabio Veronesi, and Daniele Rosellini. 2014. An overview of the last 10 years of genetically engineered crop safety research. Critical Reviews in Biotechnology. 34 (1): 77-88.

Putnam, Hilary. 1975. The Meaning of 'Meaning'. Minnesota Studies in the Philosophy of Science 7: 215-271. Repr. in: Putnam, Hilary. 1975. Mind, Language and Reality: Philosophical Papers Vol.2. Cambridge MA: Cambridge University Press.

Rozin, Paul. 2005. Meaning of 'natural': Process more important than content. Psychological Science 16: 652-658.

Sagoff, M. 2001. Genetic engineering and the concept of the natural. Philosophy and the Policy Quarterly, 21(1): 2-10.

Scott-Thomas, Caroline. 2013. Poland latest European country to ban GM crops http://www.foodnavigator.com/Policy/Poland-latestEuropean-country-to-ban-GM-crops Retrieved 26.08.2017. 
Siipi, Helena. 2013. Is Natural Food Healthy? Journal of Agricultural and Environmental Ethics 26 (4):797-812.

Siipi, Helena. 2015. Is Genetically Modified Food Unnatural? Journal of Agricultural and Environmental Ethics 28 (5):807-816.

Thompson, Paul. 1997. Food Biotechnology in Ethical Perspective. London: Blackie Academic and Professional.

Thompson, Paul. 2000. Are genetically engineered foods natural? A bioethicist responds. Purdue News https://www.purdue.edu/uns/html4ever/0009.Thompson.natural.html

Torres Gonzalez, Obdulia. 2018. Claves para comprender la resistencia de los colectivos antivacunas: una controversia científico-tecnológica pública. Revista de Humanidades de Valparaíso 6 (11): 7-37.

Verhoog, Henk, Mirjam Matze, Edith Lammerts van Bueren, and Ton Baars. 2003. The Role of the Concept of the Natural (Naturalness) in Organic Farming. Journal of Agricultural and Environmental Ethics 16(1): 29-49

Walton, Douglas N. 1996. Fallacies Arising From Ambiguity. Netherlands: Springer.

Wager, Robert. 2014. 'Pseudo-science nonsense' about GMOs designed to scare, not educate. Genetic Literacy Project.

https://geneticliteracyproject.org/2014/08/18/pseudo-sciencenonsense-about-gmos-designed-to-scare-not-educate/ Retrieved 15.07.2018.

Wikforss, Asa. 2008. Semantic Externalism and Psychological Externalism. Philosophy Compass, 3(1): 158-181. 